\title{
Nitrogen transfer in a Caribbean mutualistic network: editorial comment on the feature article by Cantrell et al.
}

\author{
Tamar L. Goulet ${ }^{1}$
}

Received: 8 October 2015 / Accepted: 13 October 2015 / Published online: 16 November 2015

(C) Springer-Verlag Berlin Heidelberg 2015

Coral reefs are flourishing ecosystems in the midst of nutrient-poor oceanic deserts. In the current issue, Cantrell et al. provide an interesting twist on how corkscrew sea anemones may obtain sufficient nitrogen levels in the oligotrophic waters. The contribution of organisms' nitrogenous waste products to the metabolism of corals and other cnidarians has been explored at several scales. Meyer et al. (1983) and Meyer and Schultz (1985) demonstrated that schools of juvenile French and white grunts resting over coral heads contributed significant amounts of nutrients to the corals beneath them. On the other end of the spectrum, a pair of anemonefish can supply $100 \%$ of their host sea anemone's nitrogen uptake (Roopin and Chadwick 2009). Cantrell et al. set out to determine the nitrogenous contribution of the spotted cleaner shrimp Periclimenes yucatanicus and Pederson's cleaner shrimp Ancylomenes pedersoni to their host, the corkscrew sea anemone Bartholomea annulata. The nitrogenous waste produced by the small shrimp was insufficient to meet the daily demands of their host sea anemone. Cantrell et al., however, deduce that through the shrimps' role as cleaners, they attract coral reef fish to the vicinity of the anemone, and these fish may contribute significant levels of nitrogen. Consequently, through a complex mutualistic network, multiple organisms benefit. This study highlights the importance of investigating ecological relationships in the context of the habitat, the environmental conditions, and the other organisms found in the environment.

\section{References}

Meyer JL, Schultz ET (1985) Migrating haemulid fishes as a source of nutrients and organic matter on coral reefs. Limnol Oceanogr 30:146-156

Meyer JL, Schultz ET, Helfman GS (1983) Fish schools: an asset to corals. Science 220:1047-1049

Roopin M, Chadwick NE (2009) Benefits to host sea anemones from ammonia contributions of resident anemonefish. J Exp Mar Biol Ecol 370:27-34

Responsible Editor: U. Sommer.

Tamar L. Goulet

tlgoulet@olemiss.edu

1 Department of Biology, University of Mississippi,

P.O. Box 1848, University, MS 38677, USA 